CASE REPORT

\title{
Brodie Bite: A Clinical Challenge
}

\author{
Ashish Agrawal
}

\begin{abstract}
Treatment of the posterior crossbite (Brodie bite) case is always challenging for orthodontics. The case requires meticulous treatment planning and is often difficult and time-consuming to treat Brodie bite. This kind of malocclusion develops partially because of lingual tipping of the lower segments, and partially because of a lower jaw too small, relative to the maxilla. A young male 12 years of age came to the dental department with chief complaints of unable to chew food and with lower jaw teeth contained within the upper jaw. Clinical examination revealed class II div I malocclusion, increased overjet and lingually locked upper left lateral incisor with just one occlusal contact at the left first molar region (mandibular teeth contained within the maxillary dentition). Though there are various treatment options available such as extractions, expansion, dental arch compensation, or orthognathic surgery for treating Brodie bite, the best treatment option should be chosen, which requires proper diagnosis. This article discusses one such case that was diagnosed and planned as three-phase treatment with two modifications in mechanotherapy.

Keywords: Brodie bite, Class II Div I, Diagnosis, Herbst.

International Journal of Clinical Pediatric Dentistry (2020): 10.5005/jp-journals-10005-1748
\end{abstract}

\section{INTRODUCTION}

Transverse deficiency of dental arches has been a difficult problem for an orthodontist. Multiple crossbite, scissors bite, and Brodie bite are some of the challenging clinical situations. The transverse deficiency can be skeletal or dental in origin. It can manifest as unilaterally or bilaterally. Crossbite is a condition in which tooth or several teeth are abnormally positioned buccally or lingually with reference to the opposing tooth or teeth. Scissors bite is often designated for one tooth in buccal crossbite in habitual occlusion. Scissors bite on several teeth resulting from transverse skeletal deficiency is termed Brodie bite. Brodie bite occurs in $1.0-1.5 \%$ of the population. ${ }^{1,2}$ This malocclusion is rare and is often undiagnosed during the mixed dentition or early permanent dentition phase as the patient is completely asymptomatic and the problem is overlooked. If such condition prevails, it may lead to traumatic bite, tempromandibular joint (TMJ) abnormalities, or facial disharmony. Traditionally, transverse discrepancy has been treated with extractions, expansion, dental arch compensation, or orthognathic surgery. The primary problems in treating a scissors bite are (1) buccal tipping with extrusion of the maxillary molar, (2) lingual tipping with extrusion of the mandibular molar, (3) molar position that is resistant to correction, and (4) lack of space to place appliances on the palatal side of the maxillary molar and the buccal side of the mandibular molar. Various other treatment procedures have been proposed to treat scissors bite involving posterior teeth, which may include intermaxillary cross-elastic, ${ }^{3}$ multibracket appliance transpalatal arch appliance (TPA) with intramaxillary elastic, ${ }^{4,5}$ a lingual arch appliance with intramaxillary elastic, ${ }^{6}$ distraction oesteogensis, ${ }^{7}$ and mini implants. ${ }^{8}$

The clinical condition gets complicated if the patient is having Brodie bite with skeletal class II pattern. Such patient has increased overjet with retropositioned mandible and deranged occlusion. To correct the deformity, one has to plan not only to correct the $\mathrm{X}$ occlusion ${ }^{9}$ but also to correct the skeletal deformity. Class II correctors play a pivot role in such conditions. This article describes the treatment of one such patient with Brodie bite with a skeletal class II deformity. The patient in this report was treated with the
Department of Dentistry, Banaras Hindu University, Varanasi, Uttar Pradesh, India

Corresponding Author: Ashish Agrawal, Department of Dentistry, Banaras Hindu University, Varanasi, Uttar Pradesh, India, Phone: +91 9889901616, e-mail: ashishdoc2000@yahoo.com

How to cite this article: Agrawal A. Brodie Bite: A Clinical Challenge. Int J Clin Pediatr Dent 2020;13(3):288-294.

Source of support: Nil

Conflict of interest: None

fixed functional appliance (Herbst) and with few modifications done during fixed orthodontic treatment procedures. The treatment was planned in three phases, i.e., prefunctional orthodontics, functional orthodontic (Herbst appliance), and postfunction orthodontic treatment.

\section{Case Description}

\section{Diagnosis}

A 13-year-old boy was referred for the treatment at the Department of Orthodontics and Dentofacial Orthopedics, Banaras Hindu University, Varanasi, Uttar Pradesh, India. His chief complaint was difficulty in chewing. His mother said that his lower jaw is unusually positioned backward. The facial profile was convex, with posterior divergence and deep mentolabial sulcus (Fig. 1). Clinical visual treatment objective (VTO) improved the profile of the patient from convex to straight. His intraoral examination (Fig. 2) showed that the mandibular teeth telescoped in maxillary teeth bilaterally except presence of one contact in the right molar region. His intraoral examination also suggested that he had retained deciduous upper left canine (63). The retained 63 caused the upper left lateral incisor to erupt palatally, which was the possible reason for locking the growth of the mandible resulting in the retropositioned mandible and increasing the overjet. The patient had $100 \%$ deep overbite with negligible visibility of lower dentition showing that mandibular teeth are completely contained in

() The Author(s). 2020 Open Access This article is distributed under the terms of the Creative Commons Attribution 4.0 International License (https://creativecommons. org/licenses/by-nc/4.0/), which permits unrestricted use, distribution, and non-commercial reproduction in any medium, provided you give appropriate credit to the original author(s) and the source, provide a link to the Creative Commons license, and indicate if changes were made. The Creative Commons Public Domain Dedication waiver (http://creativecommons.org/publicdomain/zero/1.0/) applies to the data made available in this article, unless otherwise stated. 


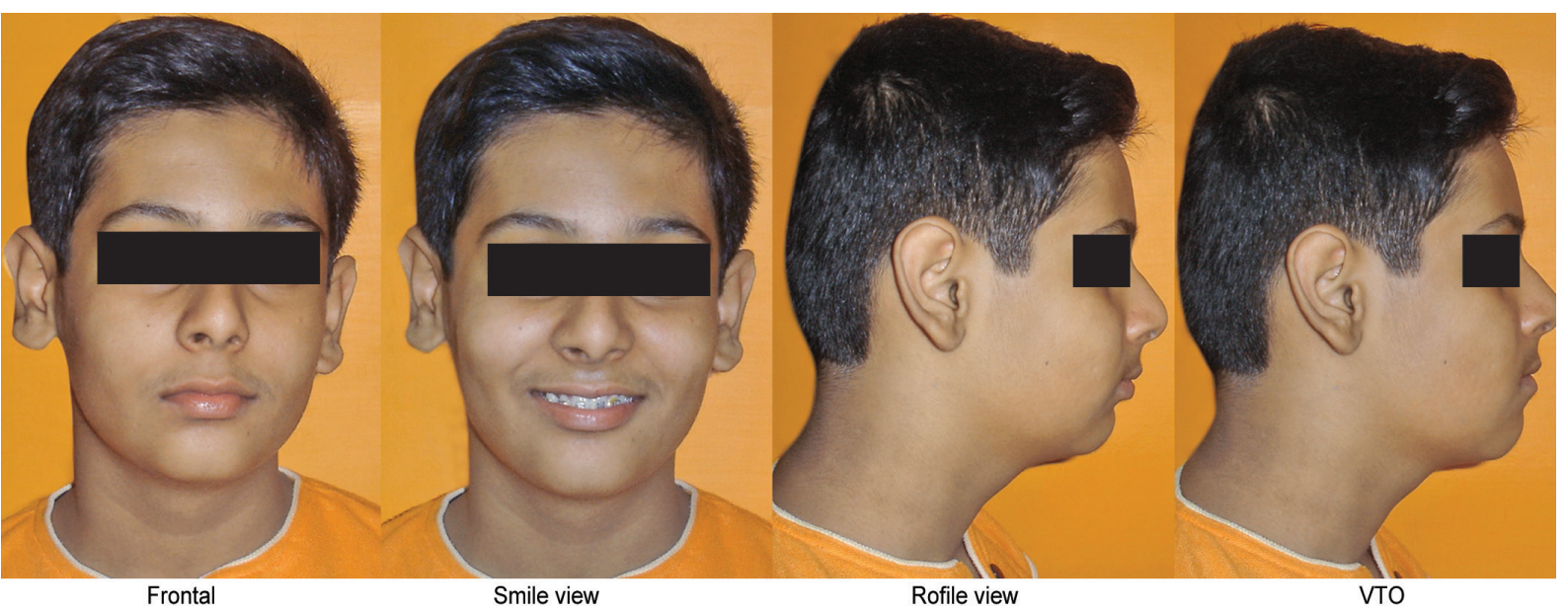

Fig. 1: Extraoral photographs (frontal, smile, profile, and VTO)

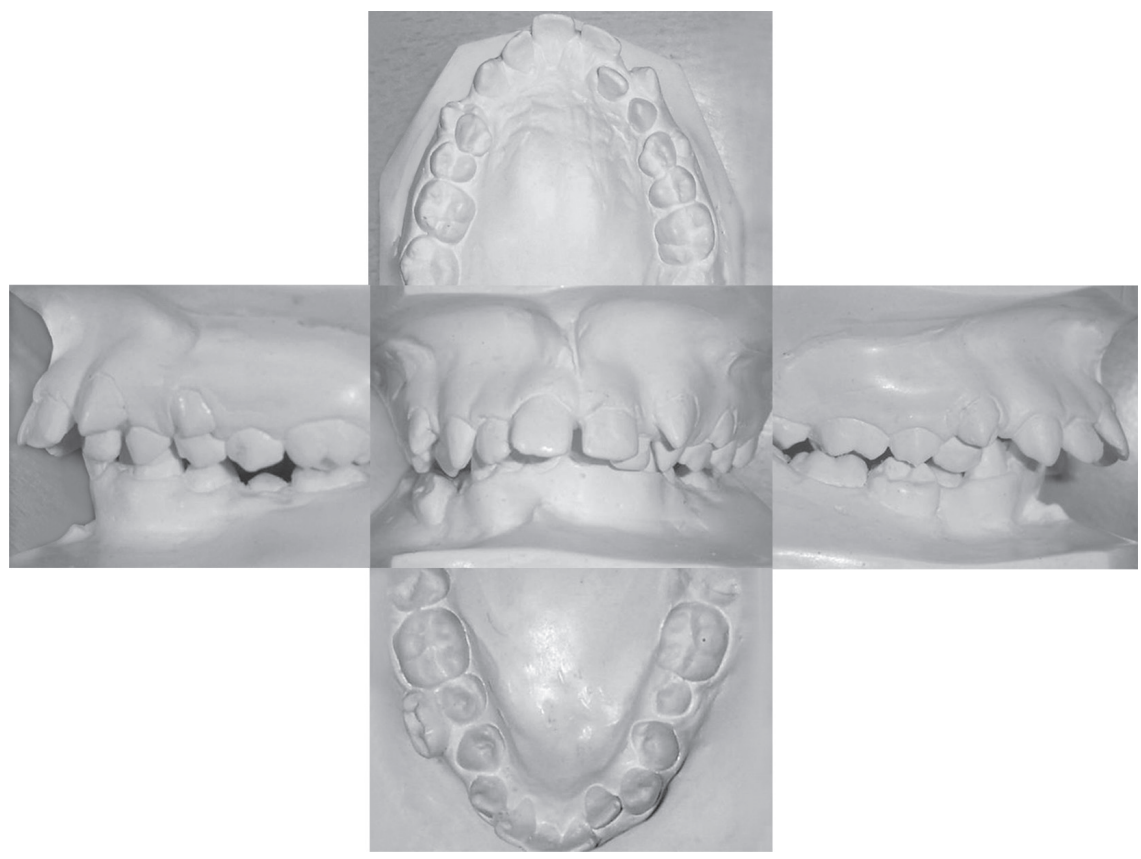

Fig. 2: Pretreatment intraoral photos

the maxillary teeth. The mandibular premolars and molars were lingually tipped with canine in class II relation. Maxillary teeth were normally positioned on their bases as compared to their mandibular counterparts.

The panoramic radiographs (Fig. 3) showed full complementary of teeth with retained lower right deciduous second molar, deciduous upper left canine and the tooth bud of third molars. The cephalometric analysis (Fig. 4) showed a skeletal class II discrepancy with point $A$, nasion and point $B$ (ANB) of $8^{\circ}$ and Frankfort mandibular plane angle of $21^{\circ}$ (a normal growth pattern). The lower incisors were normally positioned on the mandibular bases.

\section{Treatment Plan}

Three-phase treatment:

- Prefunction orthodontic (preadjusted edgewise appliance)

- Functional orthodontics (Herbst appliance)

- Postfunctional orthodontics

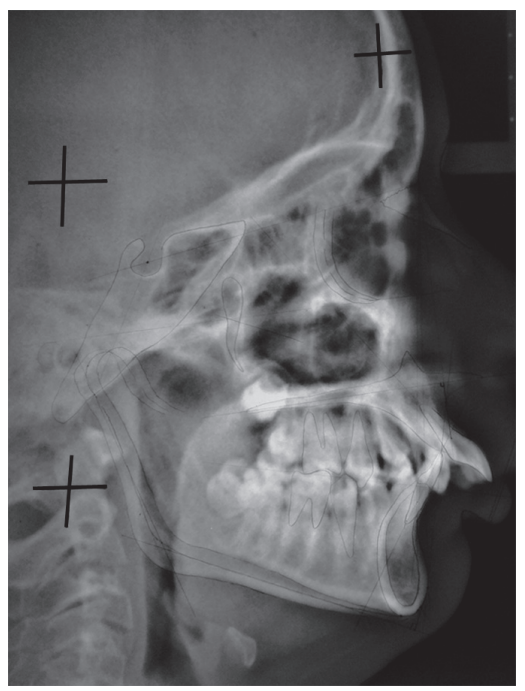

Fig. 3: Orthopantomogram pretreatment 


\section{Treatment Objectives}

- The prefunction orthodontic main objective was to correct the position of upper left lateral incisor and align the upper arch so that the actual overjet could be assessed (alignment and leveling of upper arch).

- The functional phase objective was to correct the class II skeletal relationship and bring the wider part of the mandible to the narrower region of maxillae, which will correct the bilateral crossbite or Brodie bite (correction of skeletal class II deformity, reduce overjet and overbite).

- The postfunctional objective was to obtain proper interdigitation, ideal torque, and axial inclination of all teeth and a canineguided functional occlusion.

\section{Treatment Progress}

The treatment commenced by extraction of deciduous teeth (upper left deciduous canine and right deciduous second molar). Preadjusted edgewise 022 slot MBT bracket (3M, Victory Series) prescription was chosen for the treatment. Initial $016 \mathrm{NiTi}$ wire was engaged for alignment and leveling of the upper arch to corrected lingually locked upper left lateral. Two months into the treatment, the wire was changed to a more rigid wire 018 SS followed by $17 \times$ $25 \mathrm{SS}$ and then subsequently to $19 \times 25 \mathrm{SS}$. Once proper alignment was achieved in the upper arch, the overjet was reassessed and was found to be $10 \mathrm{~mm}$ (Fixed functional). Herbst appliance (American Orthodontics) was chosen for the second phase of treatment to correct skeletal class II and to achieve normal overjet (Fig. 5). The

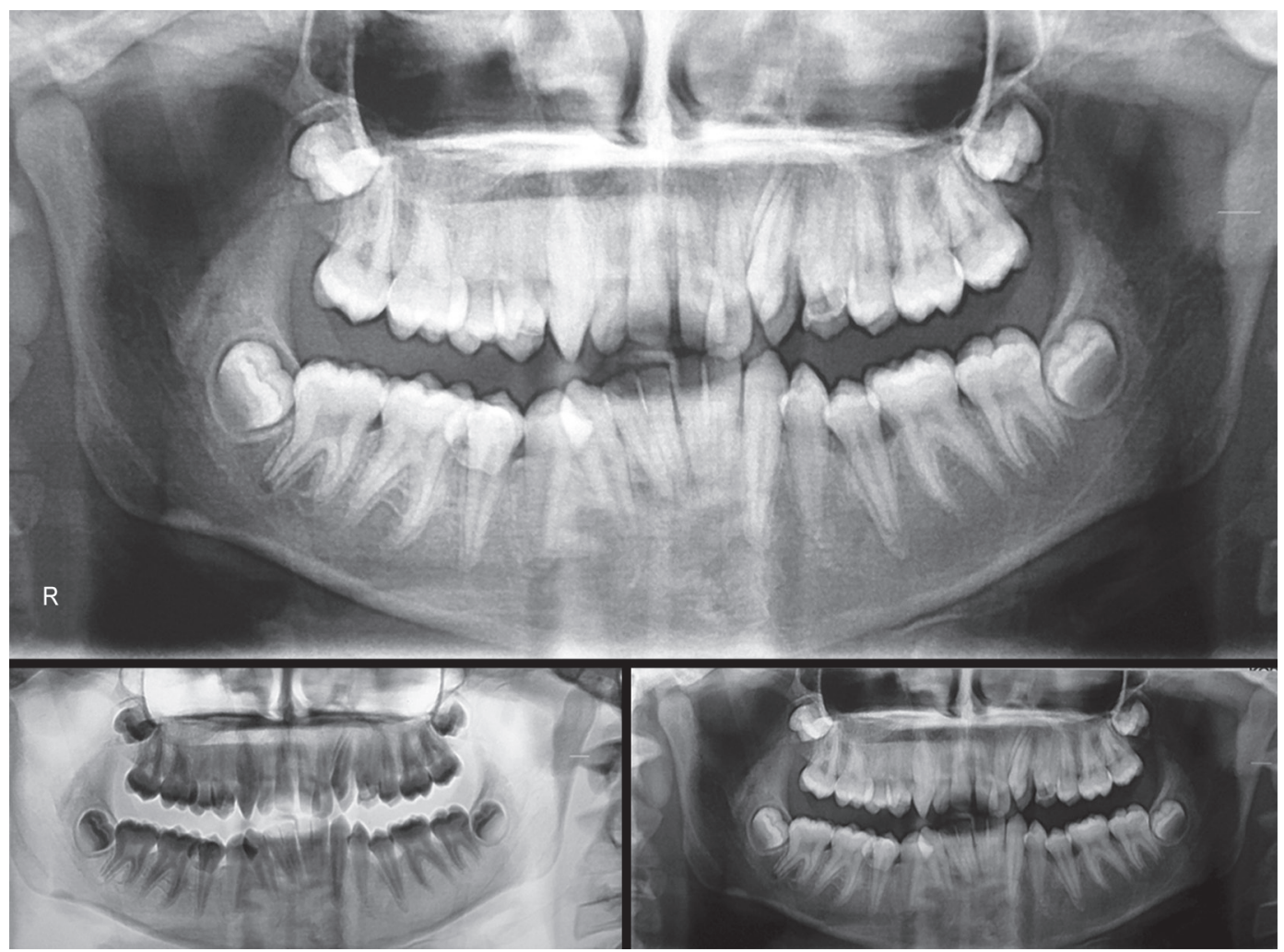

Fig. 4: Pretreatment lateral cephalogram

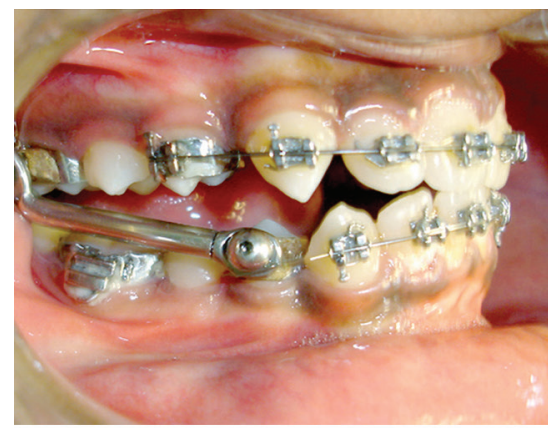

Right intraoral view

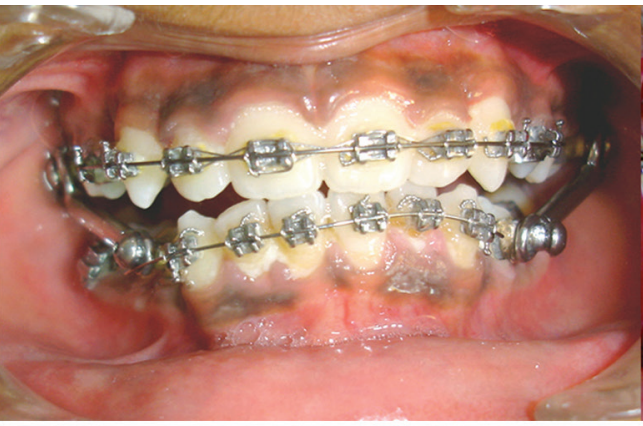

Frontal view

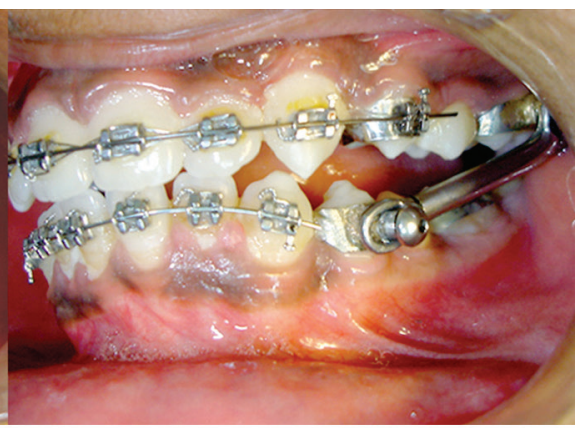

Left intraoral view

Fig. 5: Fixed functional—Herbst appliance 
total anchorage from the lower right first molar to the lower left first molar was planned for Herbst appliance. The transpalatal arch was soldered to the molars to prevent undue buccal flaring of upper molars during the functional phase. In the lower arch, the anchorage unit was modified (first modification) (Fig. 6) to bring about the correction of buccal crossbite and will also up right of the lower posterior teeth by buccal tipping of molars. For the lower anchorage unit, the lingual arch which is usually soldered to the 1 st premolar region was extended till 2 nd molar on both sides. It was expanded before cementing on to the teeth. Alignment and leveling started simultaneously in the lower arch (anterior) to reduce the overall treatment time. Ten months into the fixed functional phase, patients' overjet, complete overbite, and lingual tipping

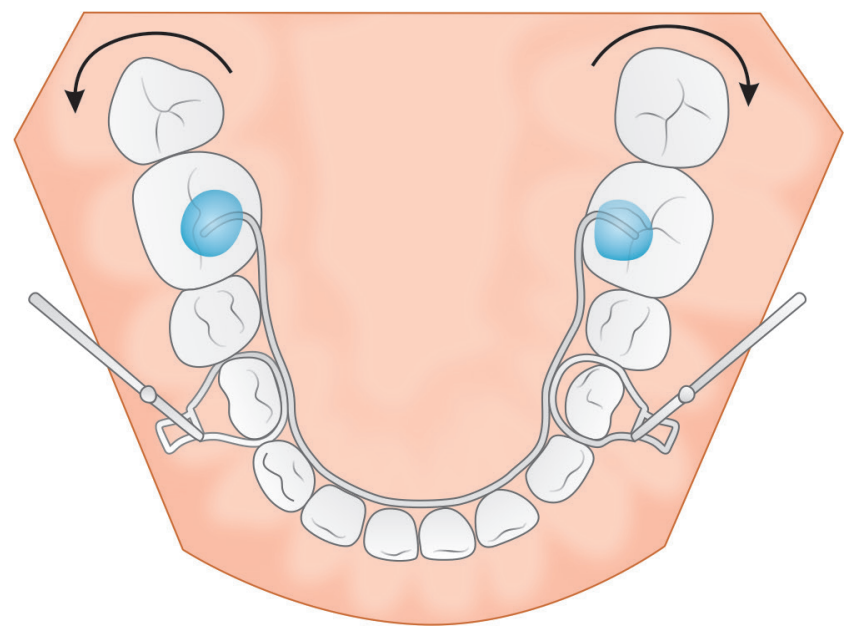

Fig. 6: Modification number 1 of lower posterior teeth were corrected (Fig. 7). During the third phase of treatment, second modification (Fig. 8) was done. The lower buccal tubes on molar bands were soldered to the molar bands in an inverted position to achieve a positive $20^{\circ}$ of torque for molar root uprighting. After initial alignment and leveling of the lower arch with $016 \mathrm{NiTi}$ the patient was put on $17 \times 25 \mathrm{NiTi}$ for a month. The torque was fully expressed in the molar tubes when the wire was sequentially changed from $17 \times 25 \mathrm{NiTi}$ to $19 \times 25 \mathrm{SS}$. The patient was fully cooperative throughout the treatment tenure, which lasted 22 months. The profiles of the patient improved from posterior divergence to straight divergence (Fig. 9). Facial esthetics were harmonious and pleasing. At the end of the treatment we did achieve excellent result with correction of Brodie bite, achieving canine-guided occlusion, class I molar and canine relation, and cusp to fosse interdigitation (Fig. 10). The final panoramic and cephalometric X-ray showed acceptable root parallelism and angulation (Figs 11 and 12). Post- and precephalometric (Fig. 13 and Table 1) readings confirmed the result obtained was both skeletal and dental as desired.

\section{Discussion}

When correcting an abnormal bite pattern such as telescoping bite (Brodie bite), it is very important to have a vertical clearance for the ease of tooth movements. A fixed mechanotherapy, which does provide the clinician a vertical clearance is often cumbersome, requires intricate wire bending for bite opening, and involves prolonged treatment time. Early diagnosis, correct assessment, and appropriate treatment planning of the case are prudent. Deep overbite, extrusion of upper and lower molars, lingual tipping of lower posterior teeth, and buccal tipping of upper posterior teeth are some of the problems encountered during the treatment of Brodie bite.

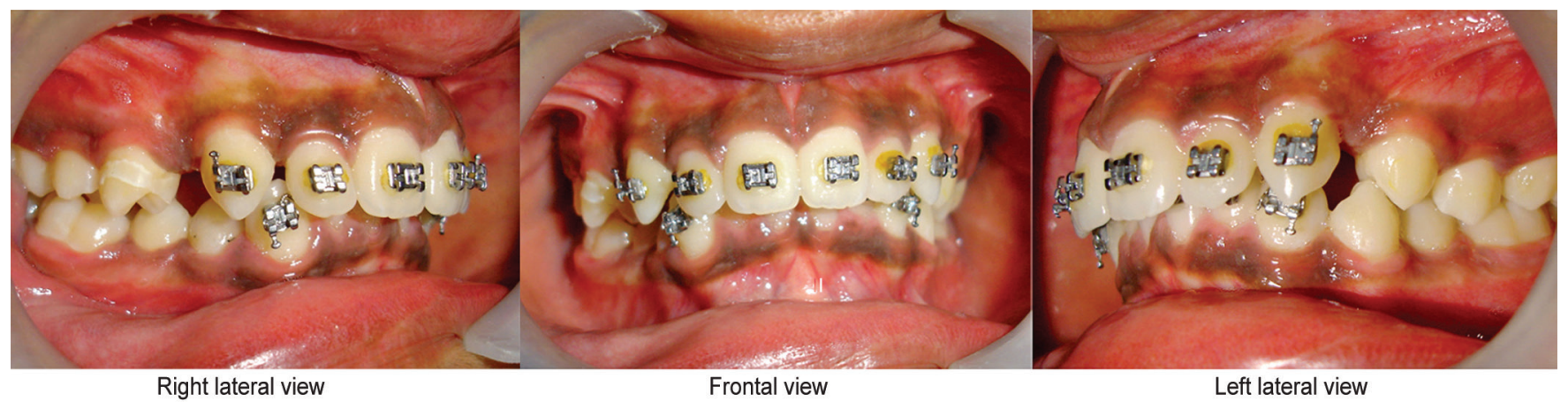

Fig. 7: Postfunctional intraoral view
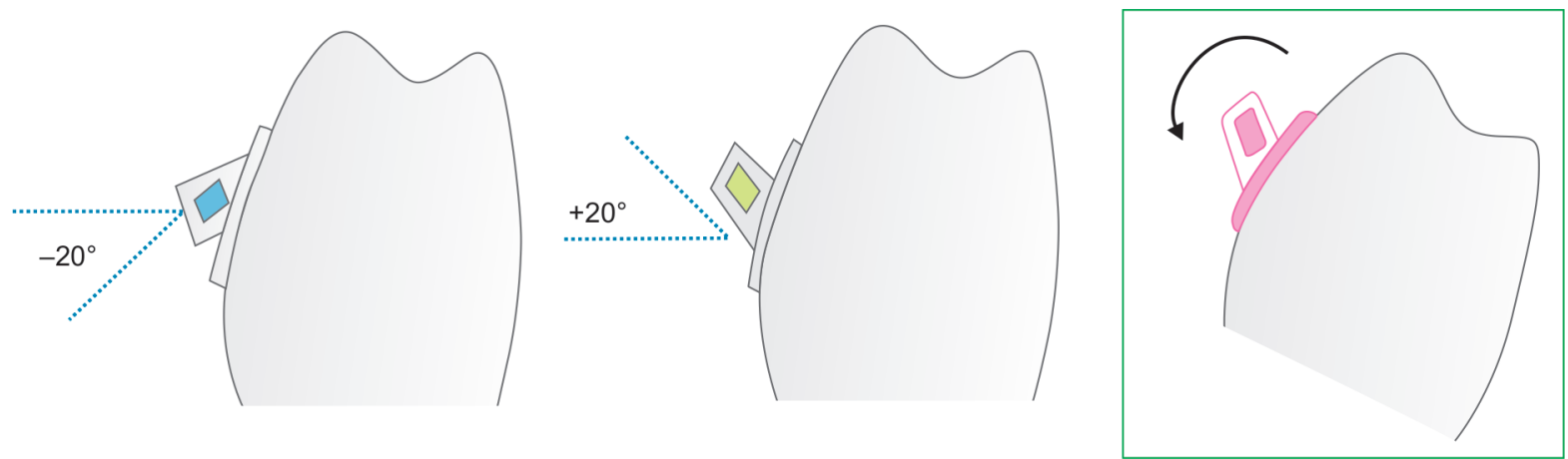

Fig. 8: Modification no. 2 with inversion of molar buccal tube 


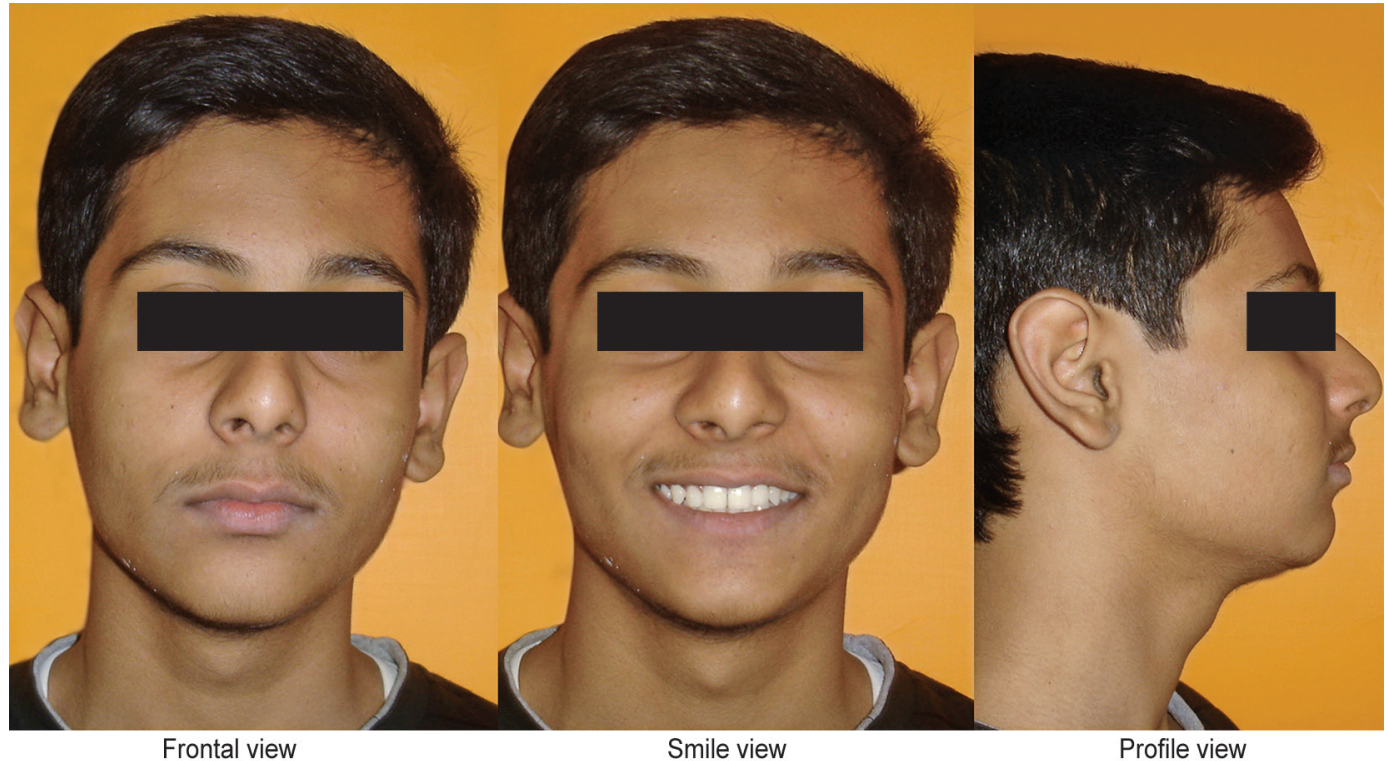

Fig. 9: Extraoral view

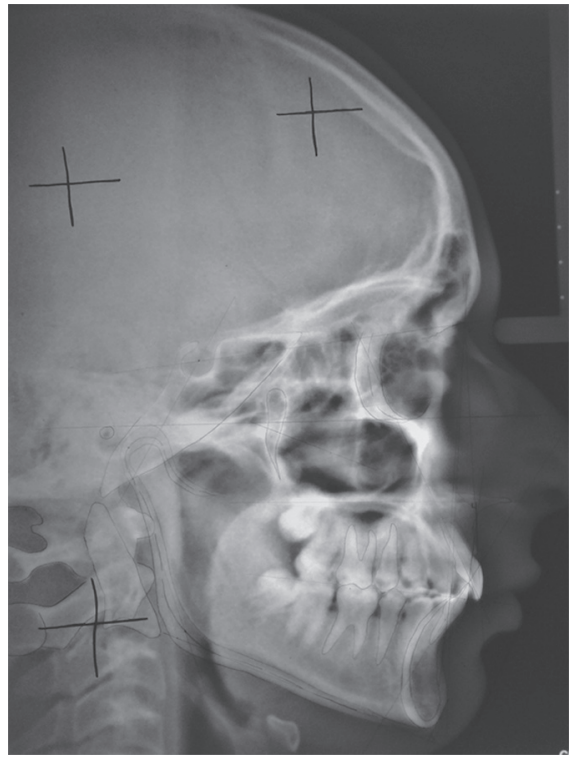

Fig. 10: Posttreatment intraoral

Various treatment modalities have been advocated for correction of Brodie bite. Surgical correction as advocated by King and Wallace ${ }^{7}$ used distraction osteogenesis of the mandible to correct the transverse discrepancy. Ramsay ${ }^{10}$ advocated the use of multiple segment Lefort surgery to correct Brodie bite. Chug et al. ${ }^{11}$ advocated the use of removal bite plates in the form of the removable bite plane for bite opening tool where others have recommended use of cross elastics ${ }^{1}$ as an adjunct to correct multiple crossbite. Though these treatment modalities are beneficial in the treatment outcome, it demands patient cooperation. The treatment should be planned keeping in mind that the undue expansion of the dental arches can affect the post-retention behavior.

Tweed ${ }^{12}$ advocated positioning the teeth upright in the basal bone to enhance stability. Strang ${ }^{13}$ argued that the teeth will relapse to position of balance within the musculature if expanded beyond the limit. Peak ${ }^{14}$ and Riedel ${ }^{15}$ found that the intercanine width returns to its pretreatment dimension and that one cannot change the arch form appreciably. Riedel ${ }^{9}$ and Shapiro ${ }^{9}$ noted that the mandibular intermolar width is uncompromising dimensions that should not be changed during treatment. After initial alignment and leveling to correct the lingually locked upper left lateral incisor, we decided for a fixed functional appliance for the case which gave us an advantage in addressing multiple treatment objectives simultaneously, i.e., opening the locked bite (by propelling the mandible forward), correction of lingually tipped molars (by modifying the anchorage system), achieving a headgear affect (bringing the molars to class I), and reducing the overjet to acceptable levels. Since the patient was 13 years and was in declining phase of growth the best chosen appliance for the case was the Herbst appliance. ${ }^{16}$ The Herbst appliance is frequently used for the treatment of class II malocclusions. The time needed for the therapy is relatively short (6-8 months) and does not depend on the patient's compliance and acts 24 hours a day. ${ }^{17}$ The anchorage system can be modified to correct the lingually tipped molars, therefore correcting the crossbite which was required in this case.

Though the correction brought about the functional therapy of 10 months was excellent. Postfunctional therapy was required for settling the bite and for proper torque expression of the posterior teeth.

Since we used PEA in this case which had a torque of $-20^{\circ}$ in the molar region, it was necessary for the case to invert the buccal tube to give a $+20^{\circ}$ torque for proper positioning of lower molars. Settling was done with vertical elastics. Throughout the treatment, the patient cooperation was excellent and the oral hygiene instruction was followed. The pseudopocket and plaque present around the lingually tipped molars were completely eliminated.

The patient was put on permanent lingual bonded retainers in the lower arch and invisible retainers in the upper arch. Good class I molar and canine relation with canine-guided occlusion was achieved for long-term stability. The end result of the treatment was good and the goals were achieved. 


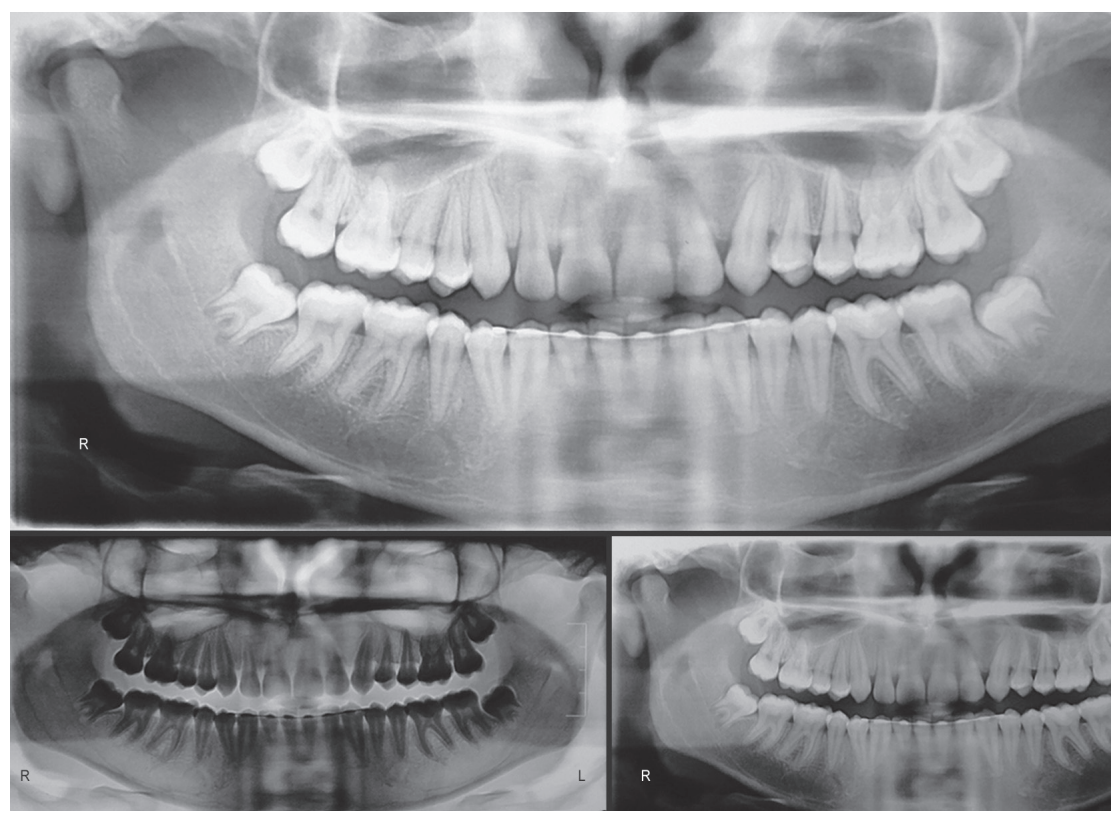

Fig. 11: Posttreatment orthopantomogram

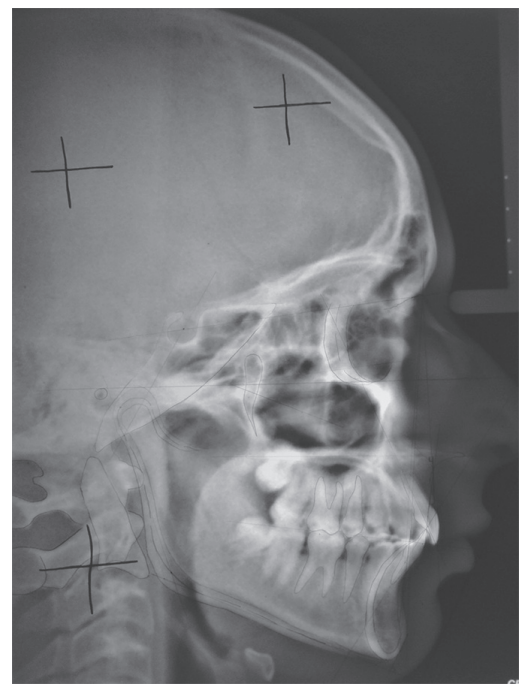

Table 1: Comparative cephalometric reading pre- and posttreatment

\begin{tabular}{lll}
\hline Measurements & $\begin{array}{l}\text { Pretreatment } \\
\text { (degrees } / \mathrm{mm} \text { ) }\end{array}$ & $\begin{array}{l}\text { Posttreatment } \\
\text { (degrees } / \mathrm{mm} \text { ) }\end{array}$ \\
\hline SNA & 83 & 84 \\
SNB & 74 & 79 \\
ANB & 10 & 4 \\
Saddle angle & 130 & 125 \\
Articular angle & 132 & 135 \\
U1-SN & 117 & 103 \\
U1-NA & $35,10 \mathrm{~mm}$ & $20,3 \mathrm{~mm}$ \\
Interincisal angle & 111 & 129 \\
L1-NB & $25,7 \mathrm{~mm}$ & $25,4 \mathrm{~mm}$ \\
Upper lip-S line & $7 \mathrm{~mm}$ & $0 \mathrm{~mm}$ \\
Lower lip-S line & $5 \mathrm{~mm}$ & $0 \mathrm{~mm}$ \\
Upper and lower lip & $6 \mathrm{~mm}$ front, $4 \mathrm{~mm}$ in & $2 \mathrm{~mm}$ behind $0 \mathrm{~mm}$ \\
to E line & front & \\
\hline
\end{tabular}

Fig. 12: Posttreatment lateral cephalogram

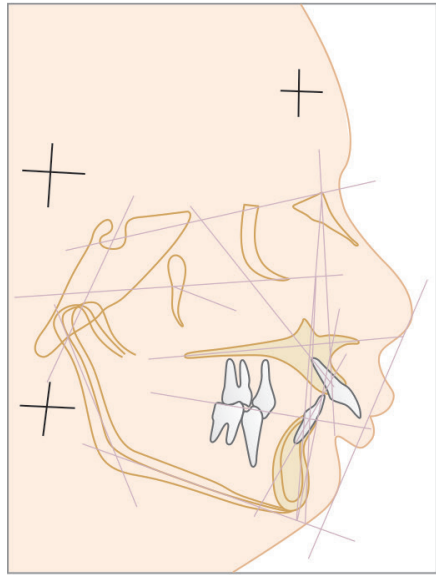

Pretreatment traced Lateral cepahalogram

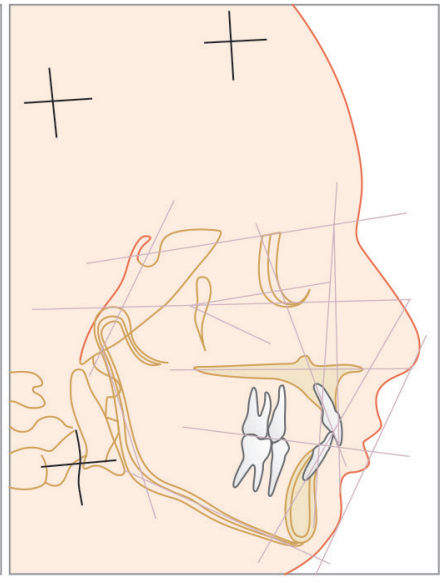

Posttreatment traced Lateral cepahalogram

Fig. 13: Comparison of post- and precephalogram 


\section{Conclusion}

Deviation from the normal teeth alignment does compromise both function and esthetics of a patient. Not only does it cause difficulty in chewing but also causes trauma to the dentition and TMJ. Associated problems with the periodontal and alveolar bone do follow. Therefore, it is important that the dental arches and teeth should be in harmonious relation to each other. Judiciously planning the case in all respect is important for critical evaluation and treatment planning. Various treatment options are available in the hands of a clinician such as orthognathic surgery, mini implants that can correct all sorts of malocclusion, and the best suitable plan for the betterment of the patient should be chosen which can provide complete rehabilitation of the patient in terms of functionality, esthetic, and long-term stability.

\section{References}

1. Harper DL. A case report of a Brodie bite. Am J Orthod Dentofacial Orthop 1995;108(2):201-206. DOI: 10.1016/S0889-5406(95)70084-6.

2. Grewe JM, Hagan DV. Malocclusion indices: a comparative evaluation. Am J Orthod 1972;61(3):286-294. DOI: 10.1016/0002-9416(72)90080-2.

3. Proffit WR, Fields JR. Contemporary Orthodontics. 3rd ed., St Louis, MO: Mosby; 1999.

4. Kucher G, Weiland FJ. Goal-oriented positioning of upper second molars using the palatal intrusion technique. Am J Orthod Dentofacial Orthop 1996;110(5):466-468. DOI: 10.1016/S0889-5406(96)70051-3.

5. Nakamura S, Miyajima K, Nagahara K, et al. Correction of single-tooth crossbite. J Clin Orthod 1995;29(4):257-262.
6. Lim KF. Correction of posterior single-tooth crossbite. J Clin Orthod 1996;30(5):276.

7. King JW, Wallace JC. Unilateral Brodie bite treated with distraction osteogenesis. Am J Orthod Dentofacial Orthop 2004;125(4):500-509. DOI: 10.1016/j.ajodo.2003.07.005.

8. Tamamuraa N, Kurodab S, Sugawarab Y, et al. Use of palatal miniscrew anchorage and lingual multi-bracket appliances to enhance efficiency of molar scissors-bite correction. Angle Orthod 2009;79(3):577-584. DOI: 10.2319/031708-152.1.

9. Shapiro PA. Mandibular dental arch form and dimension. Am J Orthod 1974;66(1):58-70. DOI: 10.1016/0002-9416(74)90193-6.

10. Ramsay DS, Wallen TR, Bloomquist DS. Surgical orthodontic correction of bilateral buccal cross bite (Brodie bite). Angle Orthod 60(4):305-312.

11. Chug VK, Sharma VP, Tandon $P$, et al. Brodie bite with an extracted mandibular first molar in young adult: A case report. AJODO 2010;137(5):694-700.

12. Tweed $\mathrm{CH}$. Indications for the extraction of teeth in orthodontic procedure. Am J Orthod 1944;30:405-428. DOI: 10.1016/S00966347(44)90038-4.

13. Strang R. The fallacy of denture expansion as a treatment procedure. Angle Orthod 1949;19:12-22.

14. Peak JD. Cuspid stability. Am J Orthod 1956;42:608-614. DOI: 10.1016/0002-9416(56)90102-6.

15. Riedel RA. A review of the retention problem. Angle Orthod 1960;30:179-199.

16. Ruf $\mathrm{S}$, Pancherz $\mathrm{H}$. When is the ideal period for herbst therapy-early or late? Semi Orthod 2003;9(1):47-56. DOI: 10.1053/sodo.2003.34024.

17. Pancherz $\mathrm{H}$. The mechanism of Class II correction in Herbst appliance treatment. A cephalometric investigation. Am J Orthod 1982;82(2):104-113. DOI: 10.1016/0002-9416(82)90489-4. 